\title{
Effect of the number of lymph nodes examined on the survival of patients with stage I non-small cell lung cancer who undergo sublobar resection
}

\author{
Sai Yendamuri, MD, FACS,,${ }^{\mathrm{a} b}$ Samjot Singh Dhillon, MD, ${ }^{\mathrm{c}}$ Adrienne Groman, MS, ${ }^{\mathrm{d}}$ Grace Dy, MD, \\ Elisabeth Dexter, MD, ${ }^{\mathrm{a}, \mathrm{b}}$ Anthony Picone, MD, ${ }^{\mathrm{a}, \mathrm{b}}$ Chukwumere Nwogu, MD, ${ }^{\mathrm{a}, \mathrm{b}}$ Todd Demmy, MD, ${ }^{\mathrm{a}, \mathrm{b}}$ and \\ Mark Hennon, MD ${ }^{\mathrm{a}, \mathrm{b}}$
}

\section{ABSTRACT}

Objectives: Early stage lung cancer is being detected at a higher frequency with the implementation of screening programs. At the same time, medically complex patients with multiple comorbidities are presenting for surgery, with a concomitant rise in rates of sublobar resection. We sought to examine the effect of sampling lymph nodes on the outcomes of patients who undergo sublobar resection for small $(<2 \mathrm{~cm})$ stage I non-small cell lung cancer (NSCLC).

Methods: All patients in the Surveillance, Epidemiology, and End Results database from 2004 to 2013 with small $(<2 \mathrm{~cm})$ stage I NSCLC who underwent sublobar resection (wedge/segmentectomy) and no other cancer history were included. The association of the number of lymph nodes examined (LNE; categories none, 1-3, 4-6, 7-9, >9) with the overall survival as well as diseasespecific survival were examined using univariate as well as multivariate analyses while controlling for covariates such as age, size $(<1 \mathrm{~cm},>1 \mathrm{~cm})$, grade, histology (adenocarcinoma vs others), and extent of resection (wedge/segmentectomy).

Results: Data from 3916 eligible patients were analyzed. Seven hundred fifteen patients $(18.3 \%)$ had segmentectomy. No lymph nodes were examined in $49 \%$ and $23 \%$ of wedge resection and segmentectomy patients, respectively. Among all eligible patients, $1132(29 \%), 474(12 \%), 228(6 \%)$, and $328(8 \%)$ patients had 1 to 3, 4 to 6, 7 to 9 and $>9$ LNE, respectively. Univariate analyses showed significant associations between overall and disease-specific survivals with age, grade, histology, sex, extent of surgery, and LNE. The association between the number of LNE and survival remained significant even after adjusting for significant covariates including extent of sublobar resection (hazard ratio for groups with LNE 1-3, 4-6, 7-9, and $>9$ compared with $0 \mathrm{LNE}$ were $0.79,0.77,0.68$, and 0.45 for overall survival; $P<.001$ ) and $0.85,0.77,0.71$, and 0.44 for disease-specific survival $(P<.05)$, respectively. In multivariate modeling, LNE was retained as a significant variable and extent of resection was not. In patients in whom at least 1 lymph node was examined, extent of resection was not predictive of outcome.

Conclusions: Many patients having sublobar resection for early stage NSCLC in the United States do not have a single lymph node removed for pathologic examination. The number of LNE is associated with improved survival, presumably due to avoidance of mis-staging. This association seems greater than the association with extent of resection (segmentectomy vs wedge resection). Appropriate lymph node examination remains an important part of resection for lung cancer even if the resection is sublobar. (J Thorac Cardiovasc Surg 2018;156:394-402)

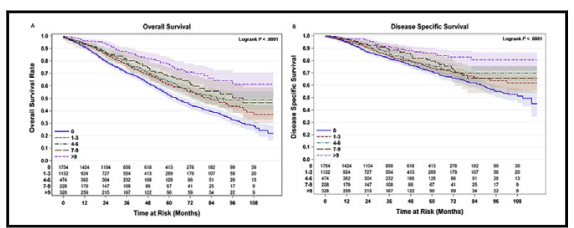

Association of number of lymph nodes examined with (A) overall survival and (B) DSS.

\section{Central Message}

In this analysis of the SEER database, the number of lymph nodes examined in patients who undergo sublobar resection for early lung cancer predicts overall and disease-specific survival.

\section{Perspective}

The importance of LNE is unclear in sublobar resection. In this study, we show that a significant proportion of patients having sublobar resection for NSCLC do not have a single lymph node examined. LNE is better with segmentectomies than with wedge resection and has prognostic importance. Lymph node sampling might be more important than extent of sublobar resection.

See Editorial Commentary page 403.

See Editorial page 378.
From the Departments of ${ }^{\text {a }}$ Thoracic Surgery, ${ }^{\mathrm{c}}$ Medicine, and ${ }^{\mathrm{d}}$ Biostatistics, Roswell Park Cancer Institute, Buffalo, NY; and ${ }^{\mathrm{b}}$ Department of Surgery, Jacobs School of Medicine and Biomedical Sciences, Buffalo, NY.

Dr. Yendamuri's work is supported by award K23 CA 149076-01A1 from the National Cancer Institute. The content is solely the responsibility of the authors and does not necessarily represent the official views of the National Cancer Institute or the National Institutes of Health.

Read at the 97th Annual Meeting of The American Association for Thoracic Surgery, Boston, Massachusetts, April 29-May 3, 2017.
Received for publication May 25, 2017; revisions received March 14, 2018; accepted for publication March 22, 2018; available ahead of print April 27, 2018. Address for reprints: Sai Yendamuri, MD, FACS, Department of Thoracic Surgery, Roswell Park Cancer Institute, Elm and Carlton St, Buffalo, NY 14263 (E-mail: sai.yendamuri@roswellpark.org). $0022-5223 / \$ 36.00$

Copyright $(2018$ by The American Association for Thoracic Surgery https://doi.org/10.1016/j.jtcvs.2018.03.113 


\section{Abbreviations and Acronyms \\ ACOSOG $=$ American College of Surgeons Oncology Group \\ LNE $=$ lymph nodes examined \\ SEER = Surveillance, Epidemiology, and End Results \\ VATS = video-assisted thoracoscopic surgery}

Scanning this QR code will take

you to a supplemental video for the article.

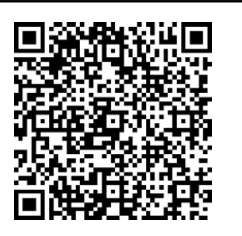

Standard surgical therapy for treatment of early stage nonsmall cell lung carcinoma for patients with adequate cardiopulmonary reserve has traditionally involved lobectomy. Historical data from the Lung Cancer Study Group's randomized trial for T1N0 patients showed decreased longterm survival and increased local recurrence for patients with tumors $<3 \mathrm{~cm}$ in size treated with sublobar resection. ${ }^{1}$ Presently, a multitude of factors has renewed interest in reassessing the role and effectiveness of sublobar resection for small peripheral lung tumors $<2 \mathrm{~cm}$ in size. These factors include, but are not limited to the implementation of lung cancer screening programs, improved imaging and staging techniques, and evolving minimally invasive surgical approaches that have expanded surgical indications for older, frail patients with increasingly complex medical comorbidities.

For patients who are not safe candidates for lobectomy, the options for sublobar resection include wedge resection or segmentectomy. Segmentectomy has generally been considered a more oncologically sound procedure. ${ }^{2,3}$ This notion is supported by results from the American College of Surgeons Surgical Oncology Group (ACOSOG) Z4032 trial showing increased nodal upstaging and better parenchymal margins with segmentectomy compared with wedge resection. ${ }^{4}$ Recently reported data exist that dispute this notion however, and for 2 large randomized trials that compared sublobar resection with lobar resection for tumors $<2 \mathrm{~cm}$ in size, the 2 sublobar procedures were included in the same treatment arm. ${ }^{5-7}$ With the potential for increased reliance on sublobar resection, further scrutiny comparing these 2 procedures is necessary. Here we report results for the extent and effect on lymph node harvest for sublobar resection with wedge resection versus segmentectomy using data from the Surveillance, Epidemiology, and End Results (SEER) database.

\section{METHODS}

The SEER database was queried for all patients with their first primary cancer diagnosed as a non-small cell lung cancer undergoing either wedge resection or segmentectomy from 2004 to 2013. The SEER Program of the National Cancer Institute collects and publishes cancer incidence and survival data from population-based cancer registries. Updated annually, and covering approximately $28 \%$ of the United States population, it is a comprehensive source of population-based information that includes stage of cancer at the time of diagnosis and patient survival data. Also included are patient demographic characteristics, primary tumor site, tumor morphologies and stages at diagnosis, first courses of treatments, and follow-up for survival statuses. $^{8}$

Only tumors $\leq 2 \mathrm{~cm}$ and stage I cancers were included in this study. Histology was classified into adenocarcinoma and others and grade was classified into grade I/II and grade III/IV. Of note, the staging system in the SEER database takes into consideration several clinical and pathologic findings. However, in the case of a patient undergoing resection, this stage would reflect pathologic stage. The number of lymph nodes examined (LNE) was analyzed as a continuous variable as well as categorized according to 2 schemata. In the first schema, they were classified into cases in which at least 1 lymph node was examined versus cases with none. In the second schema, the number of LNE was classified into 5 groups $(0,1-3,4-6,7-9,>9)$. Descriptive variables including demographic and tumor characteristics were tabulated. Patients were grouped on the basis of those undergoing sublobar resection with wedge or segmentectomy. Associations between treatment groups and demographic variables and disease status were analyzed using the Pearson $\chi^{2}$ test for categorical variables and Wilcoxon rank sum test for continuous variables. Overall survival, the primary end point, was defined as the time (in months) from diagnosis to death from any cause. Patients alive at the date of last follow-up were censored. Disease-specific survival was defined as the time (in months) from diagnosis to death from any cancer. Patients alive or who died from other causes were censored at the date of last follow-up.

Age, race, sex, grade, number of LNE, tumor size, extent of resection, and use of adjuvant radiation were considered as possible confounding factors. Univariate and multivariate proportional hazards modeling results were used to assess the effect of treatment and the confounding variables on overall and disease-specific survival. To assess possible interaction, an interaction variable using the number of LNE as a continuous variable and the extent of resection was added to the multivariable modeling. Relative prognoses were summarized using estimates and $95 \%$ confidence limits for the hazard ratio. Unadjusted differences in overall survival between the treatments were shown using Kaplan-Meier methods. All associations were considered statistically significant at an $\alpha$ error $<0.01$ $(P$ value $=.01)$. All analyses were performed using SAS version 9.4 (SAS Institute Inc, Cary, NC).

To assess the effects of missing data on outcomes, logistic regression was used to examine the missing pattern of each variable after essential selection criteria were included (ie, after step 11 of the selection criteria described in Table 1). Age of diagnosis, year of diagnosis, size of tumor, and sex were associated with the missing pattern for grade. Type of surgery was a significant predictor of the missingness of LNE and no significant predictors were found for the missing pattern of radiation-surgery sequence. A sensitivity analysis using multiple imputation methods was implemented. The imputation model was specified to covariates, as well as time to death or censoring, and the censoring indicator. For ease of fitting and comparison, some covariates were simplified relative to the original model. The race covariate was simplified to 2 levels (nonwhite, reference: white). Number of LNE, grade, and radiation surgery sequence were specified as continuous variables. Ten imputations for the missing values were estimated using Markov Chain Monte Carlo methods. 


\section{RESULTS}

Table 1 shows the effects of each exclusion criteria on the study sample size. After exclusion of patients as described previously, 3916 qualified for further analysis. Demographic and tumor characteristics are summarized in Table 2. These included 715 patients who underwent a segmentectomy $(18.3 \%)$ and 3201 who underwent a wedge resection $(81.7 \%)$. No differences in age, sex, and race was seen in patients who underwent either procedure. Most of the tumors were adenocarcinomas. A greater proportion of patients who underwent wedge resection had T2 tumors $(16.1 \%$ vs $13.0 \% ; P=.04)$ as well as adjuvant radiation therapy $(5.4 \%$ vs $3.1 \% ; P=.03)$. However, as expected, a greater proportion of patients who had a segmentectomy had larger $(1-2 \mathrm{~cm})$ tumors $(83.4 \%$ vs $76.9 \%$; $P<.001)$. Only $50.5 \%$ of patients who had a wedge resection, and $76.5 \%$ of patients who had a segmentectomy had at least 1 lymph node examined at pathology.

Univariate analyses confirmed the relationship of age, sex, race, tumor grade, histology, and tumor size with overall as well as disease-specific survival (Table 3). Segmentectomy was associated with statistically significantly better overall survival but not disease-specific survival compared with wedge resection. The examination of at least 1 lymph node conferred an important survival advantage in overall (odds ratio, $0.66 ; P<.001$ ) as well as diseasespecific survival (odds ratio, $0.71 ; P<.001$; Figure 1). Upon stratification of the number of LNE, an incremental increase in overall as well as disease-specific survival was seen with the number of LNE (Figure 2).
Multivariate analyses (Table 4) confirmed all the associations noted previously with 1 notable exception. After adjusting for all potential confounders, segmentectomy was no longer associated with a survival advantage. In fact, in patients in whom at least 1 lymph node was examined, there were no differences in either overall or disease-specific survival in patients who underwent segmentectomy versus wedge resection for early non-small cell lung carcinoma (Figure 3). In addition, the interaction variable between the number of LNE and the extent of resection was the first variable to be excluded in the model.

To assess the effect of missing variables on the associations seen, a sensitivity analysis was performed as previously described. This analysis was performed on the patients who satisfied basic inclusion criteria $(n=4572)$. Of the 4572 satisfying the inclusion criteria; 19 records had missing radiation surgery sequence data, 260 had missing number of lymph node examined, and 400 had missing grade, resulting in a total of $14 \%$ of the records with at least 1 variable missing. As stated in the previous results, the complete-case analysis included 3922 patients. The results of this analysis are summarized in Table 5. As shown in the table, the missing data did not change the association between LNE and survival.

\section{DISCUSSION}

In this analysis of the SEER database, we show that anatomic segmentectomy performed for early stage nonsmall cell lung cancer results in higher lymph node yield compared with wedge resection, and that increased lymph

TABLE 1. Selection criteria for the study population

\begin{tabular}{|c|c|c|c|c|}
\hline & \multirow[b]{2}{*}{ Condition } & \multirow[b]{2}{*}{$\mathbf{N}$} & \multicolumn{2}{|c|}{ Missing } \\
\hline & & & $\mathbf{n}$ & $\%$ \\
\hline 1 & Select collaborative stage schema & $1,105,779$ & & 0.00 \\
\hline 2 & 2003 Onward & 562,421 & & 0.00 \\
\hline 3 & Select only primary cases & 438,354 & & 0.00 \\
\hline 4 & Select first and only cancer & 430,710 & & 0.00 \\
\hline 5 & Select hist types & 375,050 & & 0.00 \\
\hline 6 & Select sites & 375,050 & & 0.00 \\
\hline 7 & Select $M$ stage 0 & 158,423 & 34,836 & 9.29 \\
\hline 8 & Select $N$ stage 0 & 84,900 & & 0.00 \\
\hline 9 & Select T stage $<$ II & 61,757 & & 0.00 \\
\hline 10 & Select tumor sizes $<2 \mathrm{~cm}$ & 22,039 & 1045 & 1.69 \\
\hline 11 & Select patients who received wedge/lobe (surgery codes 21,22 ) & 4572 & 91 & 0.41 \\
\hline 12 & Select only cases with known number of LNs examined & 4312 & 260 & 5.69 \\
\hline 13 & Eliminate neoadjuvant radiation or unknown surg rad seq & 4294 & 18 & 0.42 \\
\hline 14 & No unknown grades & 3922 & 372 & 8.66 \\
\hline 15 & Delete patients who had radiation before surgery & 3916 & & \\
\hline
\end{tabular}

hist, Histology; $L N$, lymph node; surg rad seq, surgery radiation sequence. 
TABLE 2. Patient demographic and clinical characteristics

\begin{tabular}{|c|c|c|c|c|}
\hline Characteristic & Wedge & Segmentectomy & Overall & $P$ value \\
\hline Overall, n (\%) & $3201(81.7)$ & $715(18.3)$ & $3916(100)$ & \\
\hline Age, mean $\pm \mathrm{SD}$ & $69.3 \pm 9.6$ & $68.8 \pm 9.7$ & $69.2 \pm 9.6$ & .3 \\
\hline \multicolumn{5}{|l|}{ Race, n (\%) } \\
\hline White & $2776(86.7)$ & $617(86.3)$ & $3393(86.6)$ & .4 \\
\hline Black & $265(8.3)$ & $68(9.5)$ & $333(8.5)$ & \\
\hline Other & $160(5.0)$ & $30(4.2)$ & $190(4.9)$ & \\
\hline \multicolumn{5}{|l|}{ Gender, n (\%) } \\
\hline Male & $1356(42.4)$ & $278(38.9)$ & $1634(41.7)$ & .09 \\
\hline \multicolumn{5}{|l|}{ Grade, n $(\%)$} \\
\hline $\mathrm{I} / \mathrm{II}$ & $2188(68.4)$ & $525(73.4)$ & $2713(69.3)$ & .01 \\
\hline $\mathrm{III} / \mathrm{IV}$ & $1013(31.6)$ & $241(26.6)$ & $1203(30.7)$ & \\
\hline \multicolumn{5}{|l|}{ Histology, n (\%) } \\
\hline Adeno & $1976(61.7)$ & $449(62.8)$ & $2425(61.9)$ & 6 \\
\hline Others & $1225(38.3)$ & $266(37.2)$ & $1491(38.1)$ & \\
\hline \multicolumn{5}{|l|}{ Radiation after surgery, $\mathrm{n}(\%)$} \\
\hline Yes & $173(5.4)$ & $22(3.1)$ & $195(5.0)$ & .03 \\
\hline \multicolumn{5}{|l|}{$\mathrm{T}$ stage, $\mathrm{n}(\%)$} \\
\hline $\mathrm{T} 1$ & $2687(83.9)$ & $622(87.0)$ & $3309(84.5)$ & .04 \\
\hline $\mathrm{T} 2$ & $514(16.1)$ & $93(13.0)$ & $607(15.5)$ & \\
\hline \multicolumn{5}{|l|}{ First of 2 or more primaries, $n(\%)$} \\
\hline Yes & $642(20.1)$ & $117(16.4)$ & $759(19.4)$ & .02 \\
\hline \multicolumn{5}{|l|}{ Size, $\mathrm{n}(\%)$} \\
\hline$\leq 1 \mathrm{~cm}$ & $740(23.1)$ & 119 (16.6) & 859 (21.9) & $<.001$ \\
\hline $1-2 \mathrm{~cm}$ & $2461(76.9)$ & $596(83.4)$ & $3057(78.1)$ & \\
\hline Lymph nodes examined, mean $\pm \mathrm{SD}$ & $2.6 \pm 4.7$ & $4.4 \pm 6.0$ & $2.9 \pm 5.0$ & $<.001$ \\
\hline \multicolumn{5}{|l|}{ At least 1 lymph node examined, $\mathrm{n}(\%)$} \\
\hline Yes & $1615(50.5)$ & $547(76.5)$ & $2162(55.2)$ & $<.001$ \\
\hline \multicolumn{5}{|l|}{ Lymph nodes examined, n (\%) } \\
\hline 0 & $1586(49.5)$ & $168(23.5)$ & $1754(44.8)$ & $<.001$ \\
\hline 1 to 3 & $867(27.1)$ & $265(37.1)$ & $1132(28.9)$ & \\
\hline 4 to 6 & $344(10.7)$ & $130(18.2)$ & $474(12.1)$ & \\
\hline 7 to 9 & $170(5.3)$ & $58(8.1)$ & $228(5.8)$ & \\
\hline$>9$ & $234(7.3)$ & $94(13.1)$ & $328(8.4)$ & \\
\hline \multicolumn{5}{|l|}{ Death status, $\mathrm{n}(\%)$} \\
\hline Died (other) & $489(15.3)$ & $90(12.6)$ & $579(14.8)$ & .006 \\
\hline Died (NSCLC) & $643(20.1)$ & $118(16.5)$ & 761 (19.4) & \\
\hline Alive & 2069 (64.6) & 507 (70.9) & $2576(65.8)$ & \\
\hline
\end{tabular}

SD, Standard deviation; Adeno, adenocarcinom; NSCLC, non-small cell lung cancer.

node examination is associated with better survival. The association of LNE with overall survival was stronger than any association on the basis of specific procedure (wedge resection or segmentectomy). This increased survival associated with increasing LNE might be a result of reduction in stage misclassification. Patients who underwent wedge resection had higher grade (grade III/IV) tumors, but they were smaller in size. A larger proportion of patients who underwent segmentectomy had tumors between 1 and $2 \mathrm{~cm}$, which, in multivariate analysis was associated with increased risk of long-term mortality. However, a larger number of patients having a wedge resection had T2 disease, presumably due to visceral pleural invasion, which is known to be associated with a poorer prognosis. Having at least 1 lymph node examined was associated with a survival benefit (Video 1).

For patients with reduced cardiopulmonary reserve, sublobar resection is a viable alternative to lobectomy. Despite generalized acceptance that segmentectomy is a better cancer surgery than wedge resection, a large proportion of patients today undergo wedge resection for definitive treatment for small early stage lung cancers. Only $18 \%$ of patients reported in this study underwent segmentectomy. Reasons for this are likely multifactorial, including less 
TABLE 3. Univariate analyses examining the association of clinical variables with OS and DSS

\begin{tabular}{|c|c|c|c|c|}
\hline Outcome variable & Dependent variable & Reference & Estimate $(95 \%$ CI $)$ & $P$ value \\
\hline \multirow[t]{15}{*}{ OS } & Age & & $1.03(1.03-1.04)$ & $<.001$ \\
\hline & Grade (III/IV) & Grade (I/II) & $1.42(1.27-1.58)$ & $<.001$ \\
\hline & Histology (other) & Histology (adeno) & $1.46(1.31-1.62)$ & $<.001$ \\
\hline & Nodes (yes) & Nodes (no) & $0.66(0.60-0.74)$ & $<.001$ \\
\hline & Nodes (1-3) & Nodes (0) & $0.75(0.66-0.85)$ & $<.001$ \\
\hline & Nodes (4-6) & Nodes (0) & $0.68(0.56-0.81)$ & $<.001$ \\
\hline & Nodes (7-9) & Nodes (0) & $0.61(0.47-0.79)$ & $<.001$ \\
\hline & Nodes $(>9)$ & Nodes (0) & $0.40(0.31-0.52)$ & $<.001$ \\
\hline & Race (black) & Race (white) & $0.99(0.82-1.21)$ & $<.953$ \\
\hline & Race (other) & Race (white) & $0.67(0.51-0.90)$ & .007 \\
\hline & Sex (female) & Sex (male) & $0.68(0.61-0.76)$ & $<.001$ \\
\hline & Size $(1-2 \mathrm{~cm})$ & Size $(\geq 1 \mathrm{~cm})$ & $1.39(1.02-1.60)$ & $<.001$ \\
\hline & Segmentectomy & Wedge & $0.83(0.71-0.96)$ & $<.013$ \\
\hline & Nodes (n) & & $0.95(0.93-0.96)$ & $<.001$ \\
\hline & Year of diagnosis & & $0.95(0.92-0.97)$ & $<.001$ \\
\hline \multirow[t]{15}{*}{ DSS } & Age & & $1.02(1.01-1.03)$ & $<.001$ \\
\hline & Grade (III/IV) & Grade (I/II) & $1.56(1.35-1.80)$ & $<.001$ \\
\hline & Histology (other) & Histology (adeno) & $1.32(1.14-1.52)$ & $<.001$ \\
\hline & Nodes (yes) & Nodes (no) & $0.71(0.62-0.82)$ & $<.001$ \\
\hline & Nodes (1-3) & Nodes $(0)$ & $0.82(0.69-0.96)$ & .017 \\
\hline & Nodes (4-6) & Nodes (0) & $0.71(0.56-0.91)$ & .006 \\
\hline & Nodes (7-9) & Nodes (0) & $0.66(0.47-0.93)$ & .018 \\
\hline & Nodes $(>9)$ & Nodes $(0)$ & $0.41(0.29-0.59)$ & $<.001$ \\
\hline & Race (black) & Race (white) & $1.10(0.86-1.40)$ & .46 \\
\hline & Race (other) & Race (white) & $0.61(0.41-0.91)$ & .016 \\
\hline & Sex (female) & Sex (male) & $0.70(0.61-0.81)$ & $<.001$ \\
\hline & Size $(1-2 \mathrm{~cm})$ & Size $(\geq 1 \mathrm{~cm})$ & $1.36(1.13-1.65)$ & .001 \\
\hline & Segmentectomy & Wedge & $0.83(0.68-1.01)$ & .064 \\
\hline & Nodes (n) & & $0.95(0.93-0.97)$ & $<.001$ \\
\hline & Year of diagnosis & & $0.94(0.90-0.97)$ & $<.001$ \\
\hline
\end{tabular}

$C I$, Confidence interval; $O S$, overall survival; $D S S$, disease-specific survival.

technical complexity associated with wedge resection, shorter surgery times associated with less anesthesia time, and higher chance of having the procedure completed by a minimally invasive approach. ${ }^{5}$ The desire to keep a procedure minimally invasive might affect surgical planning because established results for video-assisted thoracoscopic surgery (VATS) lobectomy have been shown to be superior to thoracotomy, especially for elderly, frail, "high risk" patients. ${ }^{9,10}$ Peripheral lesions might fall on the anatomic boundary of a segment making wedge resection more suitable for obtaining adequate parenchymal margins. The observed data confirm that many surgeons believe it is an acceptable procedure for specific scenarios. This has led to continued studies, largely retrospective in nature, comparing the 2 procedures. ${ }^{11-14}$ Unfortunately, when comparing wedge resection with segmentectomy, well balanced comparative studies are limited. An interesting observation in this analysis, that when controlled for the number of LNE, segmentectomy no longer had a survival advantage over wedge resection (Figure 2). A similar finding has recently been shown by Altorki et al. ${ }^{5}$ This raises the question of the necessity of performing a complex segmentectomy when a wedge resection with adequate lymph node sampling might be adequate. Although this important question cannot be answered by the retrospective analysis presented in this report, these results support the conduct of future studies to support or refute this observation.

Initial standards of care for curative intent surgery for lung cancer mandated complete mediastinal lymph node 

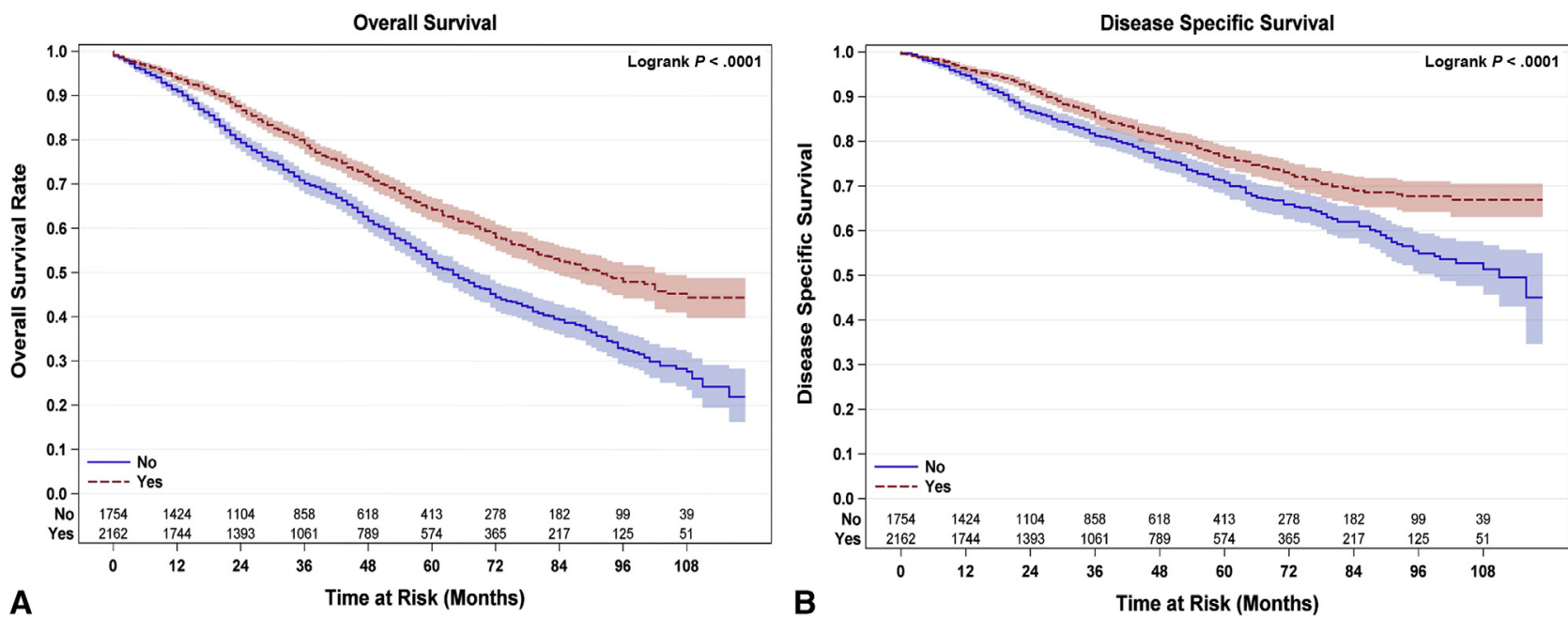

FIGURE 1. Kaplan-Meier curves showing the association of at least 1 lymph node examined (yes vs no) with overall survival (A) and disease-specific survival (B) in patients who underwent sublobar resection for early stage non-small cell lung cancer.

dissection. ${ }^{15}$ A subsequent review in 1995 showed favorable long-term survival for patients who underwent complete lymph node dissection, ${ }^{16}$ the underlying notion being that rate of recurrence and long-term survival could be potentially improved by removing occult metastatic disease. This mandate was tempered by ACOSOG Z0030, which showed no additional survival benefit for patients who underwent systematic lymph node dissection compared with those who had mediastinal lymph node sampling, as long as the extensive systematic lymph node sampling mandated by the trial was adequately performed. ${ }^{17}$ Therefore, despite lack of evidence for increased therapeutic effectiveness on its own, the importance of adequate lymph node examination is still widely held for accurate staging, prognosticating, as well as making decisions regarding the need for adjuvant systemic therapy, ${ }^{17}$ all of which affect survival. If we are to believe that lymph node evaluation is important when performing lobar resection, one can surmise the value of it when performing sublobar resection. Because of the reduced potential for treating microscopic in-transit disease because of less parenchymal resection with sublobar resection, the thoroughness of lymph node evaluation might actually be more important with sublobar resection. Not surprisingly, standardized lymph node evaluation is strictly monitored for inclusion in randomized trials examining sublobar versus lobar resection. ${ }^{6,7}$

Unfortunately, a large proportion of patients who undergo lung cancer resection in the United States do not
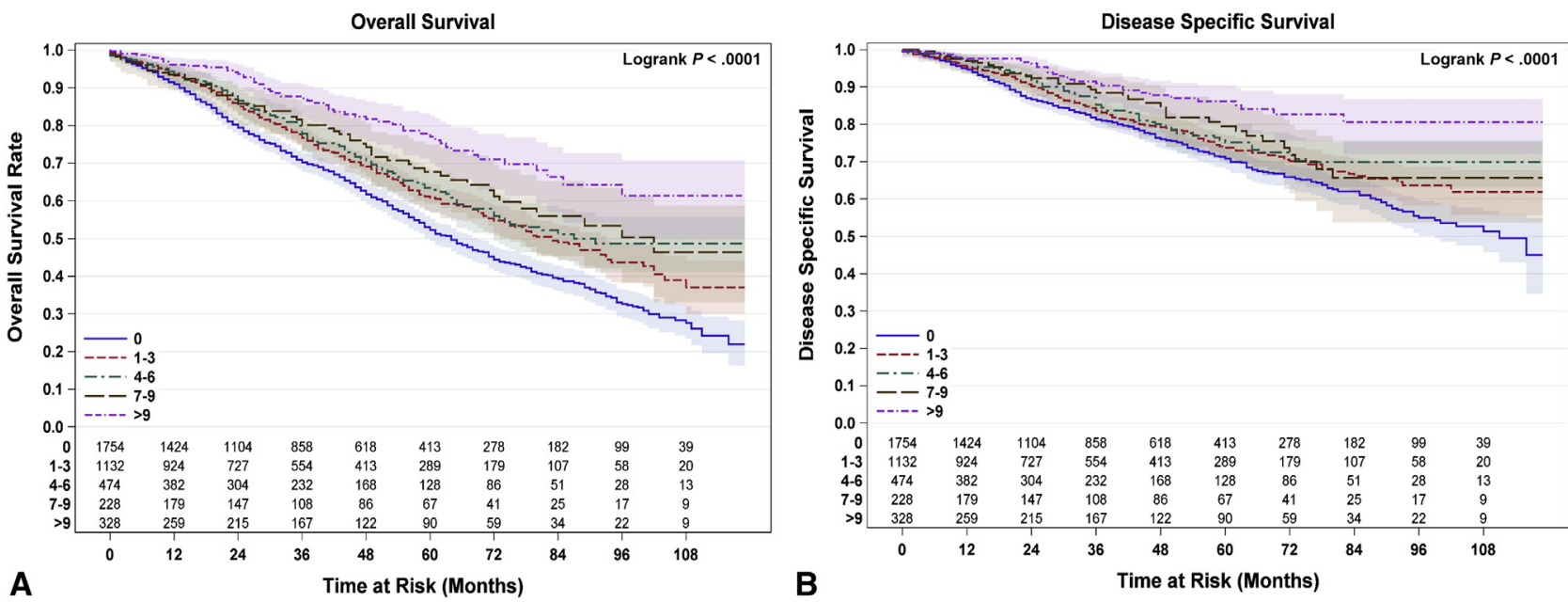

FIGURE 2. Kaplan-Meier curves showing the association of number of lymph nodes examined (grouped) with overall survival (A) and disease-specific survival (B) in patients who underwent sublobar resection for early stage non-small cell lung cancer. 
TABLE 4. Multivariate analyses examining the association of clinical variables with OS and DSS

\begin{tabular}{|c|c|c|c|c|}
\hline Outcome variable & Dependent variable & Reference & Estimate $(95 \%$ CI $)$ & $P$ value \\
\hline \multirow[t]{14}{*}{ OS } & Age & & $1.03(1.03-1.04)$ & $<.001$ \\
\hline & Grade (III/IV) & Grade (I/II) & $1.26(1.12-1.42)$ & $<.001$ \\
\hline & Histology (other) & Histology (adeno) & $1.21(1.08-1.35)$ & $<.001$ \\
\hline & Nodes (1-3) & Nodes $(0)$ & $0.79(0.70-0.90)$ & $<.001$ \\
\hline & Nodes (4-6) & Nodes $(0)$ & $0.77(0.64-0.93)$ & .006 \\
\hline & Nodes (7-9) & Nodes $(0)$ & $0.68(0.53-0.89)$ & .005 \\
\hline & Nodes $(>9)$ & Nodes $(0)$ & $0.45(0.34-0.58)$ & $<.001$ \\
\hline & Race (black) & Race (white) & $1.10(0.90-1.33)$ & $<.353$ \\
\hline & Race (other) & Race (white) & $0.67(0.50-0.89)$ & .007 \\
\hline & Sex (female) & Sex (male) & $0.69(0.62-0.77)$ & $<.001$ \\
\hline & Size $(1-2 \mathrm{~cm})$ & Size $(\geq 1 \mathrm{~cm})$ & $1.28(1.11-1.42)$ & $<.001$ \\
\hline & Segmentectomy & Wedge & $0.88(0.76-1.02)$ & .09 \\
\hline & Nodes (n) & & $0.96(0.95-0.97)$ & $<.001$ \\
\hline & Year of diagnosis & & $0.96(0.94-0.99)$ & .003 \\
\hline \multirow[t]{14}{*}{ DSS } & Age & & $1.02(1.01-1.03)$ & $<.001$ \\
\hline & Grade (III/IV) & Grade (I/II) & $1.43(1.23-1.67)$ & $<.001$ \\
\hline & Histology (other) & Histology (adeno) & $1.07(0.92-1.25)$ & .36 \\
\hline & Nodes (1-3) & Nodes $(0)$ & $0.85(0.71-1.01)$ & .062 \\
\hline & Nodes (4-6) & Nodes (0) & 0.77 (0.60-0.99) & .04 \\
\hline & Nodes (7-9) & Nodes $(0)$ & $0.71(0.50-1.00)$ & .048 \\
\hline & Nodes $(>9)$ & Nodes $(0)$ & $0.44(0.31-0.64)$ & $<.001$ \\
\hline & Race (black) & Race (white) & $1.17(0.91-1.49)$ & .22 \\
\hline & Race (other) & Race (white) & $0.62(0.41-0.92)$ & .018 \\
\hline & Sex (female) & Sex (male) & $0.70(0.61-0.81)$ & $<.001$ \\
\hline & Size $(1-2 \mathrm{~cm})$ & Size $(\geq 1 \mathrm{~cm})$ & $1.28(1.06-1.55)$ & .01 \\
\hline & Segmentectomy & Wedge & $0.89(0.73-1.08)$ & .22 \\
\hline & Nodes (n) & & $0.96(0.94-0.98)$ & $<.001$ \\
\hline & Year of diagnosis & & $0.95(0.92-0.98)$ & .003 \\
\hline
\end{tabular}

Please note that the number of lymph nodes as a continuous variable (nodes [n]) was performed in a different analysis from the categorical lymph node variable and is included here only for comparison. $C I$, Confidence interval; $O S$, overall survival; $D S S$, disease-specific survival.

have any lymph nodes sampled at the time of surgery. A 2001 review of surgical care in the United States revealed that only $57.8 \%$ of patients who had surgery as their initial treatment for lung cancer had any mediastinal lymph nodes sampled. ${ }^{18}$ If the surgical procedure was performed at a community hospital, the rate was even less, showing an obvious disconnect between what is known to be important, and what is actually being performed. Potential reasons for this discrepancy fall into patient-specific and surgeon-specific categories both of which affect the likelihood of having LNE. Limiting anesthesia time for already frail patients with reduced cardiopulmonary reserve might lead one to perform a quick wedge resection without lymph node sampling. The desire to keep a procedure minimally invasive might be another reason, although reports comparing the percentage of segmentectomies versus wedge resections being performed by VATS are conflicting. ${ }^{4,5}$ By dissecting out the venous, arterial, and bronchial structures separately, segmentectomy might simply afford more opportunities for lymph node sampling. Last, a higher proportion of segmentectomies are likely performed by thoracic surgeons, which might affect rates of lymph nodes sampling and subsequent outcomes because patients who undergo lung resection by thoracic surgeons have been shown to have improved long-term outcomes. ${ }^{19-21}$ Perhaps the examination of at least 1 lymph node during a sublobar resection could be proposed as a quality metric. In addition, our observation raises the question of the possibility of using sentinel lymph node biopsies more effectively in this patient population than the healthy patients who undergo a lobectomy.

Of interest in these results is that the survival advantage increased as the number of LNE increased, with patients 

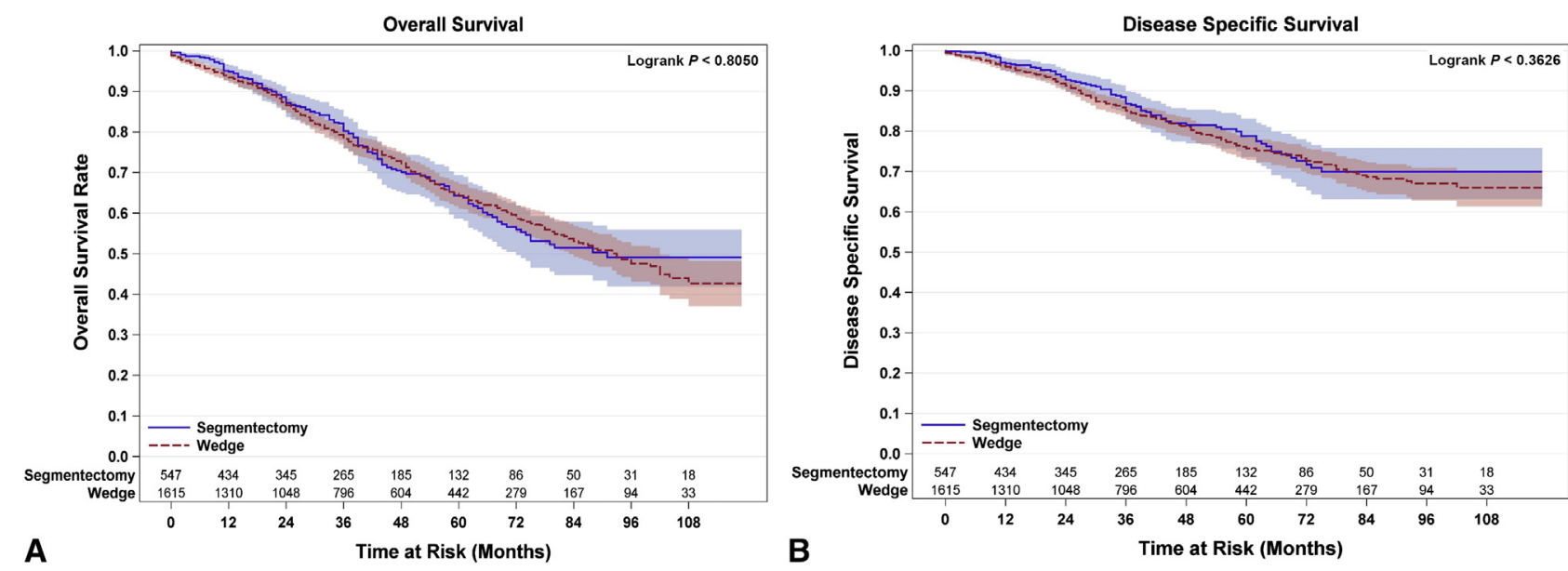

FIGURE 3. Kaplan-Meier curves showing the association of extent of sublobar resection with overall (A) and disease-specific survival (B) in patients in whom at least 1 lymph node was examined.

having 9 or more nodes examined having the greatest benefit. Although we are not suggesting that this be a quality benchmark, we hypothesize that this correlation could signify something beyond a simple reduction in stage misclassification with patients receiving adjuvant systemic treatment when nodes were positive. The linear relationship of reduced risk of death associated with an increasing number of LNE might relate to tumor biology and the patient's immune response to tumor. The mere presence of such extensive lymphadenopathy allowing for sampling of 9 lymph nodes might be an indicator of a robust patient immune response, reflecting the increasingly complex relationship involving tumor biology with the patient's immune system.

Limitations of this study are its retrospective nature and a lack of a way to verify uniform consistency with how lymph node biopsies were characterized at each institution (variation in pathology descriptions). Preoperative comorbidities, including pulmonary function tests are not included, and it is therefore difficult to adjust for these factors. Additionally, there are no data on the type of surgeon performing the procedures, which previous studies have shown to be relevant. ${ }^{19-21}$ Surgical approach is not accounted for either, which might hide subtle effects of whether VATS or thoracotomy was performed, which are actually better evaluated with increased numbers of patients as those found in multi-institution databases. No data on rates of adjuvant therapy (or return for completion lobectomy) are included, which might help assess reasons for improved long-term survival in patient groups. In addition, clinical staging has evolved significantly over the study time period, particularly with increased utilization of positron emission tomography/computed tomography. Clinical staging data as well as data with respect to comorbidities are absent in the SEER database. These are important because they might influence the choice to perform nodal dissection. One specific limitation of such a database is the lack of separate reliable clinical and pathologic staging data, limiting our ability to assess upstaging by lymph node examination as well as to perform an "intent to treat" analysis, which

TABLE 5. Comparison of association of LNE with overall survival with multiple imputation versus complete case analysis

\begin{tabular}{|c|c|c|c|c|c|c|c|c|}
\hline \multirow[b]{2}{*}{ Parameter } & \multicolumn{4}{|c|}{ Multiple imputation } & \multicolumn{4}{|c|}{ Complete case analysis } \\
\hline & $\overline{\text { HR }}$ & HR & 95\% CI limits & $P$ value & $\overline{\text { HR }}$ & HR & 95\% CI limits & $P$ value \\
\hline Age & 1.03 & 1.02 & 1.04 & $<.0001$ & 1.03 & 1.02 & 1.04 & $<.0001$ \\
\hline LNE & 0.96 & 0.95 & 0.97 & $<.0001$ & 0.96 & 0.95 & 0.98 & $<.0001$ \\
\hline Grade & 1.24 & 1.14 & 1.33 & $<.0001$ & 1.24 & 1.15 & 1.34 & $<.0001$ \\
\hline Histology & 1.17 & 1.05 & 1.31 & .0043 & 1.14 & 1.01 & 1.28 & .0311 \\
\hline Race & 1.11 & 0.95 & 1.29 & .1972 & 1.1 & 0.93 & 1.29 & .2732 \\
\hline Sex & 0.70 & 0.63 & 0.77 & $<.0001$ & 0.71 & 0.63 & 0.79 & $<.0001$ \\
\hline Size & 1.23 & 1.08 & 1.40 & .0016 & 1.25 & 1.08 & 1.44 & .0023 \\
\hline $\begin{array}{l}\text { Surgery (segmentectomy vs } \\
\text { wedge) }\end{array}$ & 0.83 & 0.73 & 0.96 & .011 & 0.88 & 0.76 & 1.02 & .0938 \\
\hline Year of diagnosis & 0.96 & 0.94 & 0.99 & .0014 & 0.96 & 0.94 & 0.99 & .0047 \\
\hline
\end{tabular}

$H R$, Hazard ratio; $C I$, confidence interval; $L N E$, number of lymph nodes examined. 


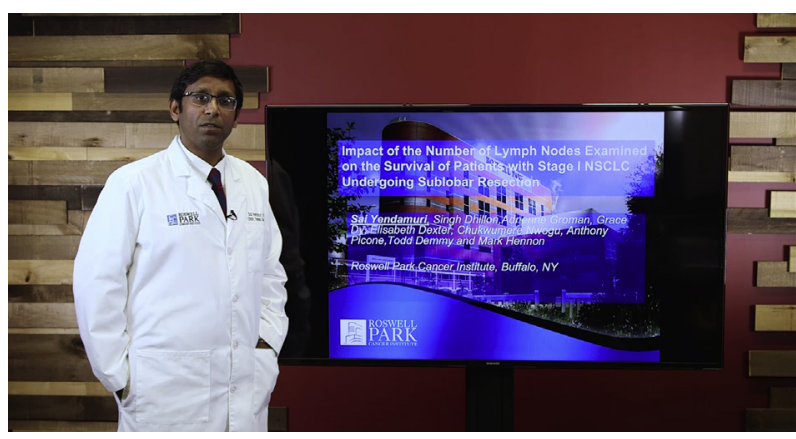

VIDEO 1. The video summarizes the findings of the study and its significance to the practicing thoracic surgeon. Video available at: https://www. jtcvs.org/article/S0022-5223(18)30895-X/fulltext.

would be useful. In addition, the SEER database has missing data that might skew the results. To assess this effect, a sensitivity analysis was performed, which suggests that this proportion of missing data did not influence the outcome of the study. However, the effect of missing data upstream of this patient selection point cannot be adequately assessed and remains an untested limitation. Strengths of the study are the large patient numbers, which are only achievable by querying large multi-institution databases. The finding that only $50 \%$ of patients who underwent wedge resection had even 1 lymph node sampled is consistent with previous reports from smaller prospective, randomized trials (ACOSOG Z4032), which adds confidence to the accuracy of the data being analyzed.

\section{CONCLUSIONS}

Sublobar resection with anatomic segmentectomy compared with wedge resection results in increased lymph node examination, which is associated with increased survival in univariate and multivariate analysis compared with patients with no lymph nodes obtained. Because the surgical procedure itself did not confer any advantage with multivariate analysis, continued emphasis must focus on adequate lymph node analysis at the time of surgery, and not necessarily the extent of resection.

\section{Conflict of Interest Statement}

Authors have nothing to disclose with regard to commercial support.

\section{References}

1. Ginsberg RJ, Rubinstein LV. Randomized trial of lobectomy versus limited resection for T1N0 non-small cell lung cancer. Ann Thorac Surg. 1995;60:615-23.
2. Smith CB, Swanson SJ, Mhango G, Wisnivesky JP. Survival after segmentectomy and wedge resection in stage I non-small cell lung cancer. J Thorac Oncol. 2013;8:73-8.

3. Sienel W, Dango S, Kirschbaum A, Cucuruz B, Hörth W, Stremmel C, et al. Sublobar resections in stage 1A non-small cell lung cancer: segmentectomies result in significantly better cancer related survival than wedge resections. Eur J Cardiothorac Surg. 2008;33:728-34.

4. Kent M, Landreneau R, Mandrekar S, Hillman S, Nichols F, Jones D, et al. Segmentectomy versus wedge resection for non-small cell lung cancer in high-risk operable patients. Ann Thorac Surg. 2013;96:1747-55.

5. Altorki NK, Kamel MK, Narula N, Ghaly G, Nasar A, Rahouma M, et al. Anatomical segmentectomy and wedge resections are associated with comparable outcomes for patients with small cT1N0 non-small cell lung cancer. J Thorac Oncol. 2016;11:1984-92.

6. ClinicalTrials.gov. Comparison of different types of surgery in treating patients with stage IA non-small cell lung cancer. Available at: https://clinicaltrials. gov/ct2/show/NCT00499330. Accessed February 2017.

7. Nakamura K, Saji H, Nakajima R, Okada M, Asamura H, Shibata T, et al. A phase III randomized trial of lobectomy versus limited resection for small-sized peripheral non-small cell lung cancer (JCOG0802/WJOG4607L). Jpn J Clin Oncol. 2010;40:271-4.

8. National Cancer Institute. Surveillance, Epidemiology, and End Results Program. Available at: https://seer.cancer.gov/about/overview.html. Accessed 2016.

9. Nwogu CE, D'Cunha J, Pang H, Gu L, Wang X, Richards WG, et al. VATS lobectomy has better perioperative outcomes than open lobectomy: CALGB 31001, an ancillary analysis of CALGB 140202 (Alliance). Ann Thorac Surg. 2015;99:399-405.

10. Demmy TL. Thoracoscopic lobectomy for impaired or complex patients: an update. Ann Thorac Surg. 2007;83:1578-81.

11. Schuchert MJ, Abbas G, Awais O, Pennathur A, Nason KS, Wilson DO, et al. Anatomic segmentectomy for the solitary pulmonary nodule and early-stage lung cancer. Ann Thorac Surg. 2012;93:1780-5.

12. Keenan RJ, Landreneau RJ, Maley RH Jr, Singh D, Macherey R, Bartley S, et al. Segmental resection spares lung function in patients with stage I lung cancer. Ann Thorac Surg. 2004;78:228-33.

13. Kilic A, Schuchert MJ, Pettiford BL, Pennathur A, Landreneau JR, Landreneau JP, et al. Anatomic segmentectomy for stage I non-small cell lung cancer in the elderly. Ann Thorac Surg. 2009;87:1662-6.

14. Nomori H, Mori T, Ikeda K, Yoshimoto K, Iyama K, Suzuki M. Segmentectomy for selected cT1N0M0 non-small cell lung cancer: a prospective study at a single institute. J Thorac Cardiovasc Surg. 2012;144:87-93.

15. Cahan WG, Watson WL, Pool JL. Radical pneumonectomy. J Thorac Surg. 1951; 22:449-73.

16. Martini N. Mediastinal lymph node dissection for lung cancer. The Memorial experience. Chest Surg Clin N Am. 1995;5:189-203.

17. Darling GE, Allen MS, Decker PA, Ballman K, Malthaner RA, Inculet RI, et al. Randomized trial of mediastinal lymph node sampling versus complete lymphadenectomy during pulmonary resection in the patient with N0 or N1 (less than hilar) non-small cell carcinoma: results of the ACOSOG Z0030 trial. J Thorac Cardiovasc Surg. 2011;141:662-70.

18. Little AG, Rusch VW, Bonner JA, Gaspar LE, Green MR, Webb WR, et al. Patterns of surgical care of lung cancer patients. Ann Thorac Surg. 2005;80:2051-6; discussion: 2056 .

19. Farjah F, Flum DR, Varghese TK Jr, Symons RG, Wood DE. Surgeon specialty and long-term survival after pulmonary resection for lung cancer. Ann Thorac Surg. 2009;87:995-1004.

20. Wood DE, Farjah F. Surgeon specialty is associated with better outcomes: the facts speak for themselves. Ann Thorac Surg. 2009;88:1393-5.

21. Tieu B, Schipper P. Specialty matters in the treatment of lung cancer. Semin Thoracic Surg. 2012;24:99-105.

Key Words: lung cancer, lymph node, sublobar, segmentectomy 